\title{
The stigma of psychiatric in-patient care
}

\author{
Jennie McCarthy, Richard Prettyman and Trevor Friedman
}

The differences in attiludes to their illness between selected groups of medical and psychiatric in-patients admilted to unlts on the same hospltal stite were investigated. Patients new to the services were asked about their willingness to disclose information about their admission to hospltal and their diagnosis to family members, friends and people af work. Psychiatric patients were more likely to want to keep their admisston and diagnosis a secret. They were also less sure of the nature of their diagnosis and the necessity of their admission. The results suggest that wider public education is needed to reduce the stigma of mental IIIness.

Although mental illness is more common than cancer it is still too often shrouded in stigma and taboo (Department of Health, 1993). Attempts have been made recently to destigmatise and raise public awareness of mental illness (Royal College of Psychiatrists, 1992) to combat the prejudice and ignorance which surround it. There is little literature available on the relationship between stigma and mental illness.

Studies on the families of the mentally ill (Wahl \& Harman, 1989) showed that almost all identified stigma as a problem for their mentally ill relative and for families in general. The most frequently cited effects of stigma were damage to self-esteem, difficulty in making and keeping friends, difficulty in finding a job and reluctance to admit to mental illness. Relatives thought that popular films about mentally ill killers, news coverage of tragedies caused by mentally ill people and jokes about mental illness were prominent sources of stigma.

Attempts have been made to reduce the experience of stigma in patients (Ling et al, 1991) by keeping their history of treatment secret, educating others about their situation and avoiding situations in which rejection might occur. None of these strategies were effective in reducing the stigma felt by the patient and it would seem that more widespread education of the population is needed.

In this study we have identified a highly selected small group of patients who were on first admission for their particular illness and therefore new to the services. We looked at the differences in attitudes between psychiatric and medical in-patients on the same hospital site. The study was approved by the local ethical committee.

\section{The study}

Thirty patients were recruited from the psychiatric and 30 from the medical unit at Leicester General Hospital. These were both modern units on a general hospital site. Patients were excluded if they had had previous admission with the same condition within the last ten years, they were under 16 years old, they were non-English speaking or they were detained under the Mental Health Act. All patients approached agreed to participate in the study: consent was ascertained verbally.

Patients were interviewed between days 3 and 10 of admission to ensure that they were in the early stages of their admission and to exclude patients with very short stays or chronic problems. Subjects were interviewed using a semi-structured interview regarding their knowledge of their diagnosis, their attitude to admission and their attitude to members of their social network having information about their illness and admission to hospital.

\section{Findings}

The 60 patients had a broad variety of medical and psychiatric diagnoses. Demographically the two groups were similar apart from the medical group being older (mean age 61.4 years c.f. 41.3 yrs; $t=4.42 ; P<0.001$ ) and more 
likely to be married than single, widowed or divorced $\left(\chi^{2}=9.74 ; P<0.05\right)$ There was a nonsignificant difference in patients' knowledge of their diagnosis with $70 \%(n=21)$ of the medical subjects being certain of their diagnosis compared with $53 \%(n=16)$ of the psychiatric group. Within the medical group $90 \%(n=27)$ of the subjects agreed that their admission had been necessary compared with $67 \%(n=20)$ of the psychiatric group, these differences were significant $\left(\chi^{2}=4.81 ; P<0.05\right)$.

Subjects were asked whether they perceived individuals from each of four groups (family, friends, workmates and employers) to be aware of various aspects of their current circumstances (admission to hospital, identity of the unit/speciality, and diagnosis). The significance of differences between psychiatric and medical patients for each of these four groups were calculated by means of $\chi^{2}$ and Fisher's exact test as appropriate. Family were defined as all first-degree relatives in contact with the patient. Significant results showed that the families of psychiatric patients were thought to be less likely to know their diagnoses than the families of medical patients $(47 \%$ v. $13 \% ; P<0.01)$, workmates of psychiatric patients were less likely to know that the patient was in hospital (53\% v. $0 \%$; $P<0.05)$ and were less likely to know the nature of the patients' illness than workmates of medical patients $(64 \%$ v. $0 \%$; $P<0.05)$. There were no significant differences for friends or employers between the two groups of patients.

Subjects were also asked about their willingness and intention to disclose information about their illness to members of their social network. Twenty per cent $(n=6)$ of psychiatric but no medical patients indicated that they would conceal their diagnosis from at least one member of their immediate family $\left(\chi^{2}=6.66 ; \quad P=0.001\right)$. Thirty-three per cent $(n=10)$ of psychiatric but no medical patients were intending to conceal diagnosis from friends, workmates or employers $\left(\chi^{2}=12.0\right.$; $P<0.001)$.

\section{Comment}

This study of a selected group of patients new to in-patient care who were admitted to medical and psychiatric units on the same site, illustrates that many psychiatric patients want to keep this event a secret. This probably reflects their own attitudes to mental illness prior to their admission, which in turn may have been shaped by friends' or relatives' experience of mental illness and psychiatric treatment. They were also likely to be less sure about the nature of their diagnosis and the necessity of their admission. It may be that certain intrinsic aspects of psychiatric illness and treatment such as the lack of diagnostic certainty and different nature of the personal trauma, compared with medical illnesses, may contribute directly to the development of negative attitudes. In certain mental disorders, particularly depressive illness, the presence of lowered self-esteem may lead to the stigma and prejudice of others being incorporated into the sufferer's view of himself or herself (Sims, 1993).

The nature of acute admission means that some patients are not able to conceal admission even if they wish to. Detained patients have no choice about their next of kin being informed and thus were excluded from this study, but they may have greater concern about divulging details of their illness and find it harder to conceal it.

Health professionals need to be aware that some patients conceal their illness, particularly from employers, as it may affect their compliance with treatment and followup. The stigma presumably reduces some patients' willingness to be admitted for psychiatric treatment.

The Health of the Nation (Department of Health, 1992) sets targets for substantially reducing deaths from suicide; this depends critically on such patients coming forward for help. Prejudice and stigma may also prevent many patients from accepting in-patient treatment and increase the use of the Mental Health Act.

It is interesting to note that doctors often have confidential arrangements made for their own psychiatric treatment and other professionals are more able to keep psychiatric treatment a secret. It may be that the general public are getting a biased impression of the frequency of mental illness and the success in its treatment. When asked about things which were most helpful in dealing with stigma, families of the mentally ill listed the following: factual information, interaction with other families of mentally ill relatives, support within the family and research findings that establish a biological basis for mental illness (Wahl \& Harman, 1989).

The number in our study was small due to the patients being such a distinct group, that is 'new in-patients' rather than re-admissions. 
The 30 psychiatric patients represent six months of admissions of this group in a unit of approximately 140 beds. However, the relatively infrequent admission of these patients gives a manageable number in whom to address the problem of stigma for themselves and their families, by education to increase understanding.

In summary, the results of this study show that this group of psychiatric patients new to the service are more likely to try and conceal their illness and admission than a comparable group of medical patients. The study indicates that more work is needed in increasing public awareness and education about mental illness to help reduce the stigma felt by sufferers. The relatively small numbers of patients falling into the group studied would allow for intensive help to be given to the patients and their families.

We hope in further work to assess whether managing patients with mental illness at home in the community enables them to be more open about their illness and reduces their perceived levels of stigma.

\section{References}

DEPARTMENT OF HEALTH (1993) Press release H93/774.

- (1992) The Health of the Nation - a strategy for health in England. HMSO.

Link, B. G., Mirotzrik, J. R., CuLlen, F. T. (1991) The effectiveness of stigma coping orientations: can negative consequences of mental illness labelling be avoided. Journal of Health \& Soctal Behaviour, 32, 302-320.

ROYAL COLLEGE OF PSYCHIATRISTS (1992) Defeat Depression: a major initiative from the Royal College of Psychitatists and the Royal College of General Practitioners, London: Royal College of Psychiatrists.

Sims, A. (1993) The scar that is more than skin deep: the stigma of depression. Brttish Journal of General Practice. 43, 30-31.

WAHL, O. F. \& HARMAN, C. R. (1989) Family vlews of stigma. Schizophrenia Bulletin, 15, 131-139.

Jennie McCarthy, Senior Registrar in Psychiatry, Arundel House, Sefton General Hospital, Smithdown Road, Liverpool. L15 2LF, Richard Prettyman, Lecturer, Department of Health Care of the Elderly, University Hospital, Nottingham NG7 2UH; and Trevor Friedman, Consultant in Liaison Psychiatry, Leicester General Hospital, Gwendolen Road, Leicester LE5 4PW 